\title{
Giant Aneurysm at the Junction of the Left Internal Carotid and Persistent Primitive Trigeminal Arteries
}

-Case Report-

\author{
Koji TsuboI, Fumiho SHIBUyA, Takashi YamadA and Tadao NosE
}

\author{
Department of Neurological Surgery, Institute of Clinical Medicine, \\ University of Tsukuba, Tsukuba, Ibaraki
}

\begin{abstract}
A 67-year-old female presented with an unruptured giant aneurysm at the junction of the left internal carotid artery (ICA) and the persistent primitive trigeminal artery (PTA), manifesting as progressive left abducens nerve paresis. The PTA was clipped by the left suboccipital approach. The aneurysm was then successfully thrombosed by ligation of the left ICA at the cervical portion following left superficial temporal artery-middle cerebral artery anastomosis. The left abducens nerve paresis improved postoperatively. Magnetic resonance imaging was of considerable value in the pre- and postoperative evaluation of the giant aneurysm.
\end{abstract}

Key words: giant aneurysm, primitive trigeminal artery, magnetic resonance imaging

\section{Introduction}

Most carotid-basilar anastomoses are coincidental findings in angiographic examinations. The primitive trigeminal artery (PTA) occurs most frequently with an incidence of $0.1-0.3 \% .{ }^{7)}$ Aneurysms are highly associated with this vascular anomaly, but aneurysms of the PTA or at the junction of the PTA and internal carotid artery (ICA) are extremely rare. We report a case of unruptured giant aneurysm at the junction of the left PTA and ICA, and discuss the treatment of this condition.

\section{Case Report}

A 67-year-old female presented with progressive left abducens nerve paresis. She had suffered from progressive right visual disturbance due to miotic retinopathy since age 18 years. One month before admission, her family noticed inadequate abduction of the left eye. She consulted an ophthalmologist and was transferred to our department. Past and family histories were not contributory.

Physical examination showed that she was general-

Received November 8, 1988; Accepted March 31, 1992 ly healthy. Her blood pressure was medically well controlled. Neurological examination disclosed no abnormality except for disturbances of right visual acuity and incomplete left abducens nerve paresis. No signs involving other cranial nerves were observed.

Computed tomographic (CT) scans revealed a clearly enhanced round mass at the left cavernous sinus (Fig. 1). Magnetic resonance (MR) images also
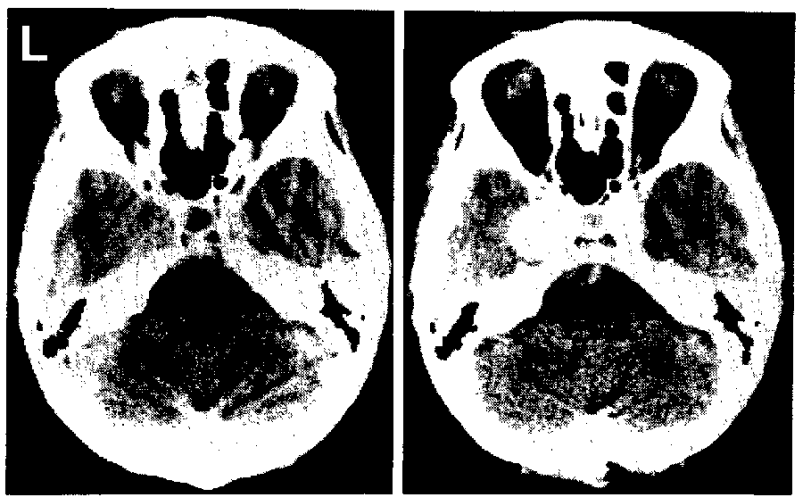

Fig. 1 Pre- (left) and postcontrast (right) CT scans on admission, showing a well-demarcated, enhanced round mass at the left cavernous sinus. 

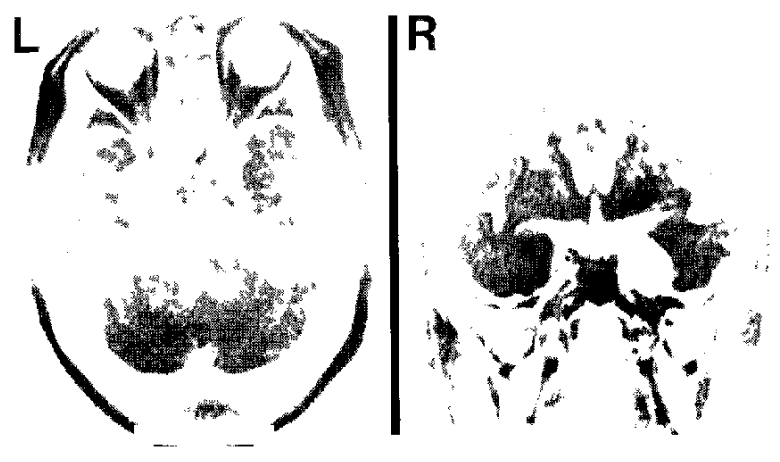

Fig. 2 Axial (left) and coronal (right) SE MR images on admission, demonstrating the mass as a signal void.
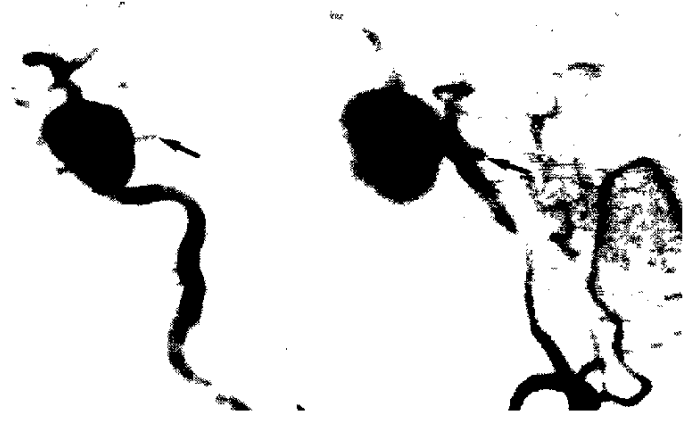

Fig. 3 left: Left carotid DSA, visualizing a giant aneurysm at the cavernous portion of the left ICA. A PTA branches from the aneurysm (arrow). right: Left vertebral DSA, showing the aneurysm from the PTA (arrow).

clearly visualized this lesion as a signal void (Fig. 2). Digital subtraction angiograms (DSAs) of the left ICA showed a giant aneurysm, $28 \times 26 \times 26 \mathrm{~mm}$, at the cavernous portion (Fig. 3 left). The PTA and the upper portion of the basilar artery were visualized via the aneurysm. Vertebral DSAs also visualized the aneurysm via the PTA (Fig. 3 right).

Proximal ligation of the ICA following extracranial-intracranial (EC-IC) bypass usually adopted to treat giant aneurysms at this site ${ }^{2,13)}$ was not considered appropriate because of the blood flow via the PTA to the aneurysm. Since the normal posterior circulation was maintained by the vertebral arteries in this case, the PTA anastomosing the aneurysm and the basilar artery could be occluded by clipping via the suboccipital approach. A distal portion of the artery close to Meckel's cave was located laterally to the trigeminal nerve and the PTA
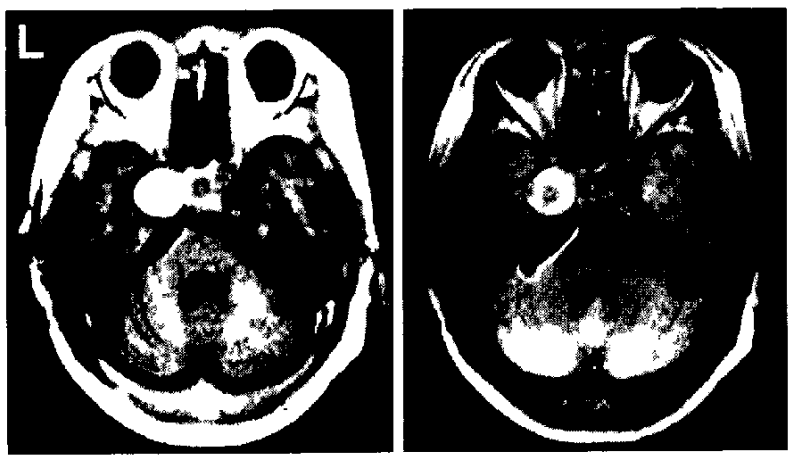

Fig. 4 IR (left) and SE (right) MR images on the 7th postoperative day, demonstrating a thrombus in the aneurysm as a high-intensity area.
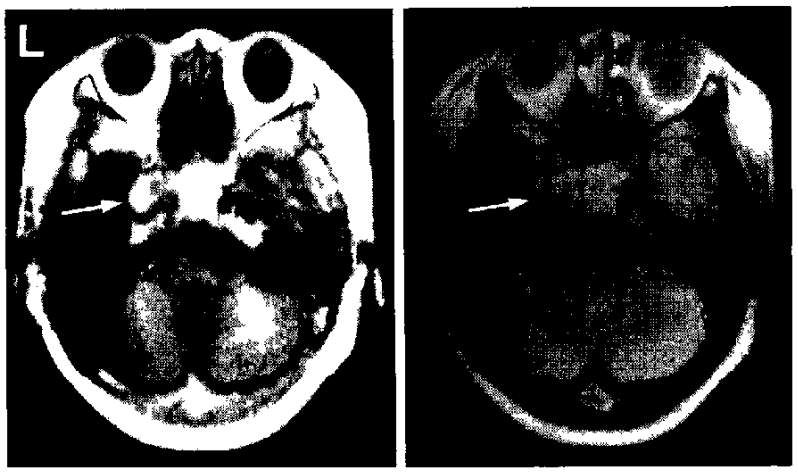

Fig. 5 IR (left) and SE (right) MR images on the 90th postoperative day. The aneurysm has shrunk markedly (arrow).

easily identified and clipped. Ten days later, the left ICA was completely occluded with an intravascular balloon catheter for 20 minutes and electroencephalograms and neurological signs monitored. This Matas test detected no abnormality. Therefore, the left ICA was ligated at the cervical portion after left superficial temporal artery-middle cerebral artery anastomosis, causing no neurological complications.

The postoperative course was uneventful. CT scans on the 7th postoperative day showed no enhancement due to the aneurysm. MR images demonstrated a well-demarcated, high-intensity round mass (Fig. 4). Left common carotid angiograms visualized the middle cerebral arteries through the anastomosed superficial temporal artery. She was discharged on the 10th postoperative day with mildly improved left abducens nerve paresis. Follow-up MR images on the 90th postoperative day showed marked shrinkage of the aneurysm (Fig. 5). 


\section{Discussion}

At least 50 cases of PTA associated with an aneurysm located on the circle of Willis have been reported. ${ }^{7.14)}$ George et al. ${ }^{3)}$ found that $14 \%$ of 233 cases with this anomalous artery had associated aneurysms. $13 \%$ of these aneurysms were on the PTA. However, giant aneurysms at the junction of the PTA and ICA are extremely rare, with only five reported cases (Table 1). ${ }^{1,5,9,11)}$ Four of these five cases were treated with an excellent outcome in the three most recent. Higashida et al. ${ }^{5)}$ successfully thrombosed an aneurysm with a detachable balloon catheter. Miyatake et al. ${ }^{9)}$ combined intravascular balloon obliteration and ICA ligation with an EC-IC bypass to thrombose the aneurysm. Our first operation was intended to occlude the PTA by direct clipping, so the suboccipital approach was selected. Other examples of direct surgical approaches to the PTA include a combined middle cranial fossa and suboccipital approach, ${ }^{8}$ and a suboccipital approach to Meckel's cave. ${ }^{91}$

The most effective treatment of giant ICA aneurysm is occlusion of the aneurysmal neck, but this is prevented in many cases including ours by the bulbous neck of the giant aneurysm. ${ }^{6)}$ An alternative is aneurysm trapping with an EC-IC bypass. ${ }^{2,6,137}$ In our case, the intracranial portion of the left ICA distal to the aneurysm was not occluded because of difficulty in preserving the patency of the left ophthalmic artery, especially important to this patient with right visual disturbance. Eguchi et al. ${ }^{2}$ considered trapping unnecessary to thrombose the aneurysm based on their analysis of 11 cases of giant intracavernous aneurysms of the ICA, because the immediate risk of trapping may be greater than the long-term cumulative risk of an untreated unruptured aneurysm.

MR imaging was very valuable in both pre- and

Table 1 Reported cases of giant ICA aneurysms associated with PTA

\begin{tabular}{lclc}
\hline \multicolumn{1}{c}{ Author (Year) } & $\begin{array}{c}\text { Age/ } \\
\text { Sex }\end{array}$ & \multicolumn{1}{c}{ Treatment } & Outcome \\
\hline $\begin{array}{c}\text { Bull }(1969)^{1 /} \\
\begin{array}{c}\text { Naruse and Odake } \\
(1979)^{11)}\end{array}\end{array}$ & $\begin{array}{l}43 / \mathrm{F} \\
73 / \mathrm{F}\end{array}$ & $\begin{array}{l}\text { ICA ligation } \\
\text { none }\end{array}$ & died \\
$\begin{array}{c}\text { Higashida et al. } \\
(1987)^{5)}\end{array}$ & $69 / \mathrm{F}$ & detachable balloon & excellent \\
$\begin{array}{c}\text { Miyatake } \text { et } \text { al. } \\
(1990)^{9)}\end{array}$ & $52 / \mathrm{F}$ & $\begin{array}{l}\text { intravascular balloon, excellent } \\
\text { EC-IC bypass, } \\
\text { ICA ligation } \\
\text { PTA clipping, } \\
\text { EC-IC bypass, } \\
\text { ICA ligation }\end{array}$ & excellent \\
\hline
\end{tabular}

postoperative evaluation of the giant aneurysm. Preoperatively, the appearance was a signal void. Seven days after ICA ligation, the intra-aneurysmal clot appeared as a well-demarcated, high-intensity round mass on both SE and IR images, consistent with the appearance of intraparenchymal hematoma. ${ }^{4,12)}$ MR imaging showed the same on the 21 st postoperative day (data not shown). As organization of the intra-aneurysmal clot progressed, the MR intensity reduced reflecting the shrinkage of the aneurysm on the 90 th postoperative day.

\section{References}

1) Bull J: Massive aneurysm at the base of the brain. Brain 92: 535-570, 1969

2) Eguchi $T$, Mayanagi $Y$, Takakura K: EC/IC bypass and ICA ligation on one-stage operation for intracavernous and giant carotid aneurysm. No Shinkei Geka 11: 1037-1046, 1983 (in Japanese)

3) George $\mathrm{AE}$, Lin JP, Morantz RA: Intracranial aneurysm on a persistent primitive trigeminal artery: Case report. $J$ Neurosurg 35: 601-604, 1971

4) Gomori JM, Grossman RI, Goldberg HI, Zimmerman RA, Bilaniuk LT: Intracranial hematomas: Imaging by high-field MR. Radiology 157: 87-93, 1985

5) Higashida RT, Halbach VV, Mehringer $\mathrm{CM}$, Hieshima GB: Giant cavernous aneurysm associated with trigeminal artery: Treatment of detachable balloon. AJNR 8: 757-758, 1987

6) Hosobuchi Y: Giant intracranial aneurysms, in Willkins RH, Rengachary SS (eds): Neurosurgery, vol 2. New York, MacGraw-Hill, 1985, pp 14041414

7) Lie TA: Variation in cerebrovascular anatomy, in Fox JK (ed): Intracranial Aneurysms, vol 1. New York, Springer-Verlag, 1983, pp 432-489

8) Merry GS, Jamieson KG: Operative approach to persistent trigeminal artery producing facial pain and diplopia. $J$ Neurosurg 47: 613-618, 1977

9) Miyatake $S$, Kikuchi $H$, Kondoh $S$, Higashi $T$, Yamagata E, Nagata I: Treatment of a giant aneurysm of the cavernous internal carotid artery associated with a persistent primitive trigeminal artery: Case report. Neurosurgery 26: 315-319, 1990

10) Morrison G, Hegarty WM, Brausch CC, Castele TJ, White RJ: Direct surgical obliteration of a persistent trigeminal artery aneurysm. $J$ Neurosurg 39: 249251,1974

11) Naruse $S$, Odake G: Primitive trigeminal artery associated with an ipsilateral intracavernous giant aneurysm: A case report. Neuroradiology 17: 259264,1979

12) Sipponen JT, Sepponen RE, Sivula A: Nuclear magnetic resonance imaging of intracranial hemorrhage in the acute and resolving phases. $J$ Comput 
Assist Tomogr 7: 954-959, 1983

13) Spetzler RF, Schuster H, Roski RA: Elective extracranial-intracranial arterial bypass in the treatment of inoperable giant aneurysms of the internal carotid artery. $J$ Neurosurg 51: 731-742, 1979

14) Wolpert SM: The trigeminal artery and associated aneurysms. Neurology (Minneap) 16: 610-614, 1966
Address reprint requests to: K. Tsuboi, M.D., Department of Neurological Surgery, Institute of Clinical Medicine, University of Tsukuba, 1-1-1 Tennohdai, Tsukuba, Ibaraki 305, Japan. 